\title{
The Post Millennium Structuralism in Teaching Children's Literature
}

\author{
Ream Odetallah \\ English Language Center, Al Ain University \\ P.O. Box 64141, Al Ain, UAE \\ Tel: 971-56-7232690Ｅ-mail: reamfathi@gmail.com
}

$\begin{array}{lcc}\text { Received: March 29, } 2013 & \text { Accepted: April 9, } 2013 \quad \text { Published: April 10, } 2013 \\ \text { doi:10.5296/ijele.v1i3.3506 } & \text { URL: http://dx.doi.org/10.5296/ijele.v1i3.3506 }\end{array}$

\begin{abstract}
This paper sheds light upon the newly existed literary movement, the post-millennium structuralism, which is a complete deviation from the last century's movements. The paper experiments the literary approach of the latest phenomenon in a digital scene retrieved from of one of the most popular stories of the nineteenth century, Alice's Adventures in Wonderland by Lewis Carroll. The approach does not only indicate the importance of the deviations in the story that goes in parallel with the pace of the technological and materialistic world as children become more consciously aware at earlier ages, but also summons the EFL educators on the new standards of teaching literature to children. The paper also manifests the psychological and academic features of the non-native English learners during their developing years and how they involuntarily and intentionally construct the new teaching trends in literature, which would never be stabled as long as education presumes.
\end{abstract}

Keywords: teaching literature, post-millennium structuralism, Alice's Adventures in Wonderland, EFL learners and English Language 


\section{Introduction}

In the late twentieth century drastic changes have occurred in the educational systems as students' more demands have been based on English Language learning through the uses of multimedia and internet materials inside classrooms. This has steered the academic learning from books to computers, projectors, interactive whiteboards and mobile phones, encouraging students to the visual and pragmatic learning strategies, which in return imposing the contemporary and modern TEFL teachers to innovate new methods for classroom instructions. It is not as simple as it may be when conducting a reading class to EFL children since literature has always been a traditional reading class time, so what is presented in this paper is the most modern way to teach literature with two examples from Lewies Carroll's Alice's Adventures in Wonder land using the post-millennium structuralism approach. This paper examines the role of literature in teaching practical grammar to young ESL learners. It will also cover how literature can be an asset in learning the culture of the target language for the means of communication, as Alptekin (2002) states that bilinguals require a profound perception of the language's culture for professional communication.

In a small study conducted to thirty two students of grades five and six from one of the best private schools in a small town, Al Ain in the United Arab Emirates, it has been verified that most students have watched the Disney Digital 3D, Alicein Wonderland, and only two students have read it. The children have been asked for the reasons of favoring watching over reading and their replies are related to modernity, quick learning, discovery, and demonstrative comprehension, whereas, class readings would require more concentration on English words to understand the story, hence it would take more time to finish the story, and that would be boring. Their replies also imply that they are quick visual learners with no interest at all in detailing the stories from start to end, disregarding the students' comprehension levels.

\section{What is Post-Millennium Structuralism?}

Since the world has become more chaotic and disturbing causing some instabilities in many of the world's educational systems, especially in Asia and the Middle east, newly adapted teaching trends have emerged struggling to keep in pace with the level of good education. Moreover, the students are seeking for what are innovational, creative, productive and optimistic to serve their learning desires, which are no longer gullible. Post-millennium structuralism in literature varies than the previous literary movements of the last century in some ways starting from structuralism to modernism. It is argued that "'Basic Texts' and 'Further Reading, are an integral part of our project to familiarize the reader with the thinking which has constructed their present field of study". (Sleden, Widdowson \& Brooker, 2005, p. 3) The next movement, post-structuralism, founded by Michael Foucault states, "I would say that this has always been my problem: the effects of power and the production of "truth." (Politics, Philosophy, Culture, p. 118)In other words, he suggests that power influences the truth because post-structuralism tells of ranks of human nature, and how the empowered can dominate the powerless in a world shaped by the political and social ranks. The post-millennium structuralism contradicts the two movements that people from all around the 
world, disregarding their social and academic ranks, can use the English Language because it is an international language. Therefore, in response to structuralism and post-structuralism simultaneously, the English language is unique when it is used professionally and accurately, but not necessarily fluently by TEFL educators. In other words, it no longer matters when a non-native speaker from anywhere around the world communicates with the American English or the British English accent mingled with the mother tongue's accent as long as the sentence structures and the speech contents are, respectively, proper and vivid. Finally, modernism resembles post-millennium structuralism that they have both emerged from the world of chaos; however, sophistication is the main focus in any language of the former movement as well as most modernist novels have one narrator that addresses the readers such as the protagonist 'Willy' in Arthur Miller's Death of a Salesman, whereas the post-millennium structuralism, whether the novels are written in the first or third person narrator, the novels are to be simplified and spiced up with some sense of humor and direct speech to receive the messages and ideas quickly for the purposes of entertaining and educating the readers of the millennium as well as indirectly acquiring the culture of the target language.

At the start of the millennium, when internet came into existence, many educationalists and readers referred to online resources and readings, and people from different parts of the world have become closer to each other through free communicative means. The result is a cocktail of different cultures, ideologies, philosophies, languages and attitudes producing a great reaction against the norms of life, hereby, education is one of the most important factors of life-a means for a better future. Also, the involvement of online media has upgraded, degraded or maintained education around the world.

Education is a broad topic to cover in one research, so this paper focuses only on experimenting the implementation of post-millennium structuralism in a scene selected from Alice's Adventures in Wonderland. For some years, literature has lost its literary taste, especially in schools with the emergence of movies, TV series and narrating CDs that have taken over the novels' privileges. In order to encourage students to become more independent in the reading skills as well as in any other skills, there are two levels in the evolution of the post-millennium structuralism which a teacher should consider in order to plant the passion of learning the second language; the deep level (how life is running or fashioned) and the surface level (teaching English to EFL students). The first level, which is about advanced technology, intercultural relations and the world's crisis and innovation, is responsible for the constitution of the surface level. The factors of the deep level must necessarily be convinced by a teacher to produce a modern learning environment; hence, the teacher would easily perceive the surface level: psych-education of the students and what teaching methodologies are recommended for a particular class. 
Post-Millennium Structuralism

(Untraditional Teaching)

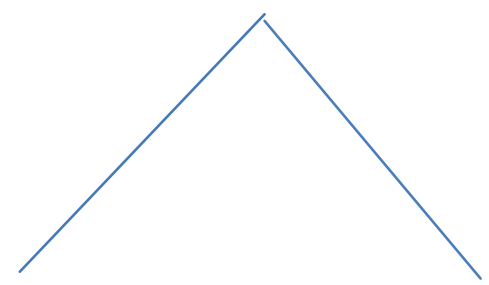

Surface Level Deep Level

(Teaching Methods)(Cultural and Modern Life Perceptions)

Figure 1. The identification of the Post Millennium Structuralism trend

Post-millennium structuralism is a new trend that follows no rules, but takes the paths of current situations. One of these paths is technology which is advancing faster than any times before in many developed and developing countries, and this is the major reason for the children's witty thoughts, analyses and perceptions. As a result, it is not accepted for a student to outwit a teacher, so new teaching methodologies must be adapted to keep in pace with today's technology such as the use of interactive whiteboards, assigning electronic homework, the use of language laboratories for instructional processes and continuous professional development trainings for teachers. Another path is the negative impact of the world's mess upon the EFL students such as the financial world crisis and the instabilities of some governments as in Syria, Egypt, Palestine, Libya, Iraq and some African and Asian countries. The uprising approach is shaped by the new generations in search for peace, love, security and optimism. Since there are no respectable rules embracing the children's future, then they would start shaping up their future improperly, and the educators, who are the people of wisdom, can liberate the victims from forbidden or improper education. They need to be enlightened with a little hope of optimism and their only way out of this misery is to become well-educated. However, the world's economic crisis and political effects on children have made them wiser or more aware of the real world. They have come to analyze situations as they are, disconnecting themselves from imagination once known as romanticism. So when reading the classical novel Alice's Adventures in Wonderland, it would be boring and a waste of time to open discussions about the talking animals, how mean or how friendly some characters are or asking them to read and to summarize certain chapters. Extending the discussion, any literary genre presents some kind of culture or implies the writers' moods or tones. The concept of using literature in a modern language classroom is to arise the learners' cultural awareness from stories that are long forgotten or not known to them, like Long (1987) who suggests that literature should be involved in classes of English for non-native learners but in another pedagogical approach..."the teaching of literature is an arid business unless there is a response, and even negative responses can create an interesting classroom situation."Finally, innovation is the most prominent factor that elevates any learner from one step to another. Innovation is "an idea, practice, or object that is perceived as new by an 
individual or other unit of adoption." (Rogers, 2003, p. 137) When a learner seeks for innovation, the gratitude goes back to the educator who is mainly or partially responsible for a learner's progress in education. Teachers who follow the traditional teaching systems are not necessarily unsuccessful in their teachings, but are not likely to bother themselves in steering their beliefs towards modern education which requires a lot of work. For instance, modern teachers would think of something new to benefit their students and to improve their teachings by making Alice's Adventures in Wonderland an exciting story to read in class, disregarding the fact that probably most of the students have read and/ or watched the story. A teacher may assign each student a character to analyze, act out, criticize or appraise along with some words they are required to learn as part of the school's syllabus. For innovation to be inevitable in a literature class, a teacher must not only contribute to a material's change or a change in his/ her teaching belief, but also is prepared for a behavioral change, for the style and the behavior of a teacher do affect the students' acceptance or rejection of a studied material.

As for the surface level factors, they are intertwined within each other, so to run a certain curriculum, a teacher must first scrutinize the students' psychological backgrounds before practicing the teaching methods inside the classrooms. Particularly, all schools are followed by certain systems and part of these systems is the curricula. However, a modern and a professional teacher can adjust a curriculum without any subtraction from or addition to it that best suits the students. For example, teaching the novel Alice's Adventures in Wonderland to EFL students may not be as easy as teaching it to native speakers of English because it is a Western story, and who are most probably, familiar with the story since the author and the learners root from the same culture. Therefore, a teacher must look for ways that should be convenient to the EFL students, even though if they are smart, modernized or wealthy. They need the easiest and the most modern way to acquire a story in the second language without sophistications. If a teacher talks about the Victorian Age and its features to have a more profound insight of the story, the students may show some kind of disinterest in this matter because they have not lived it nor have their parents or ancestors. Therefore, the methods chosen must be last-longing and effective to ensure that the students have not only learnt the story and its moral(s), but also have learnt the language and enjoyed the story.

To ensure the quality of education in a certain region, separate educational frames are to be implemented in different parts of the world. Literature is not an easy subject to many non-native students, so sticking to a stereotype and a traditional way of teaching literature to them would lead to unproductive classrooms. Teachers should crucially implement the surface level throughout a term as they teach literature to bring out the best of the EFL literature classrooms.

\section{Methods}

The researcher has visited four classes; two grade five classes and two grade six classes. Some important data has been collected before talking to the class about the story to have a good background of the students that involves their social, academic and character traits, and accordingly a reading class is conducted. 
Grade 5A has four students; Grade 5B has sixteen students; Grade 6A has five students and Grade 6B has seven students. Classes 5A and 6A are all girls and classes 5B and 6B are all boys, and this dividing system is one of the psych-education factors which the teacher should consider. Another factor is that all of the students' mother tongues are not English and they do not speak English after school, except for one boy who is from the Philippines and he is living in an Arabic speaking country, so the only way to communicate with people outside school is to use the international language, which is the English Language. Combining these two environmental factors along with the educational factor that the students' English level is mainly average, the researcher has implemented the necessary teaching methodologies in the four classrooms.

Firstly, understanding the language is not a major problem to many students since most of them enjoy the Speaking skill simply because there are not many strict rubrics to follow, on the other hand, the Grammar skill is disliked by many students because it has many fixed rules, and it is the teachers' main dilemma because they believe it is the foundation of a language. Nevertheless, this extra attention bores the students especially that they have been studying it since grade two and will continue taking it till they graduate from school. In other words, excess attention to Grammar does not reinforce their desires in learning the English language, for they consist of rules that could be easily forgotten as they continuously have to abide by the traditional rules of learning Grammar. Next is the Listening skill, which varies from one listener to another. As EFL learners, it always depends on a student's living environment and exposure to English songs and movies as well as their vocabulary. Most students are not good listeners and that has been clarified as their teachers and the researcher have repeated the contents of the questionnaires in English and in desperate cases have used the Arabic Language, the mother tongue. On the other hand, the Reading skill is the most liked skill as long as the teachers provide students with meanings, keywords, answers to oral questions and tell them what to underline as they read along, otherwise they will not manage on their own. More or less, the students are used to the spoon-feeding strategy and this must be amended to help them develop their second language as well as enjoying the reading story. Therefore, the two different methods used in the four classes (Reading A and Reading B presented below and on the next page) are independently comprehensible by the students due to the choices of modern English vocabulary and the teacher's teaching methodology by seeking for practical and hilarious activities to drill the scene into the students' minds. Finally, the Writing practice is definitely a different topic to be researched on. Writing involves all the skills discussed, and if a student does not possess at least a good level of each skill, then the chances of writing quite good would not be possible.

According to the discussed dilemmas in the preceding paragraph, literature is considered an advanced material and to understand any literary work, a student must be at least good in all the skills to guarantee the understanding of a story and its moral(s).EFL students summon on simple teaching that they can grasp, process and produce in their assignments, tests and exams. Any prepared work by a teacher must always be through an analysis of the students' standards since mostschools in the UAE, if not all, have students of multi levels in one classroom. Moreover, patience is not a trait found in many students; therefore, reading page 


\section{Macrothink}

by page or chapter by chapter may let thestudents lose the main points of a story. A teacher would more likely select important plots which are enriched with interesting, humorous, weird, appalling or overwhelming events to attract the attention of the students, and without losing the core of the story.

\subsection{Reading Method A}

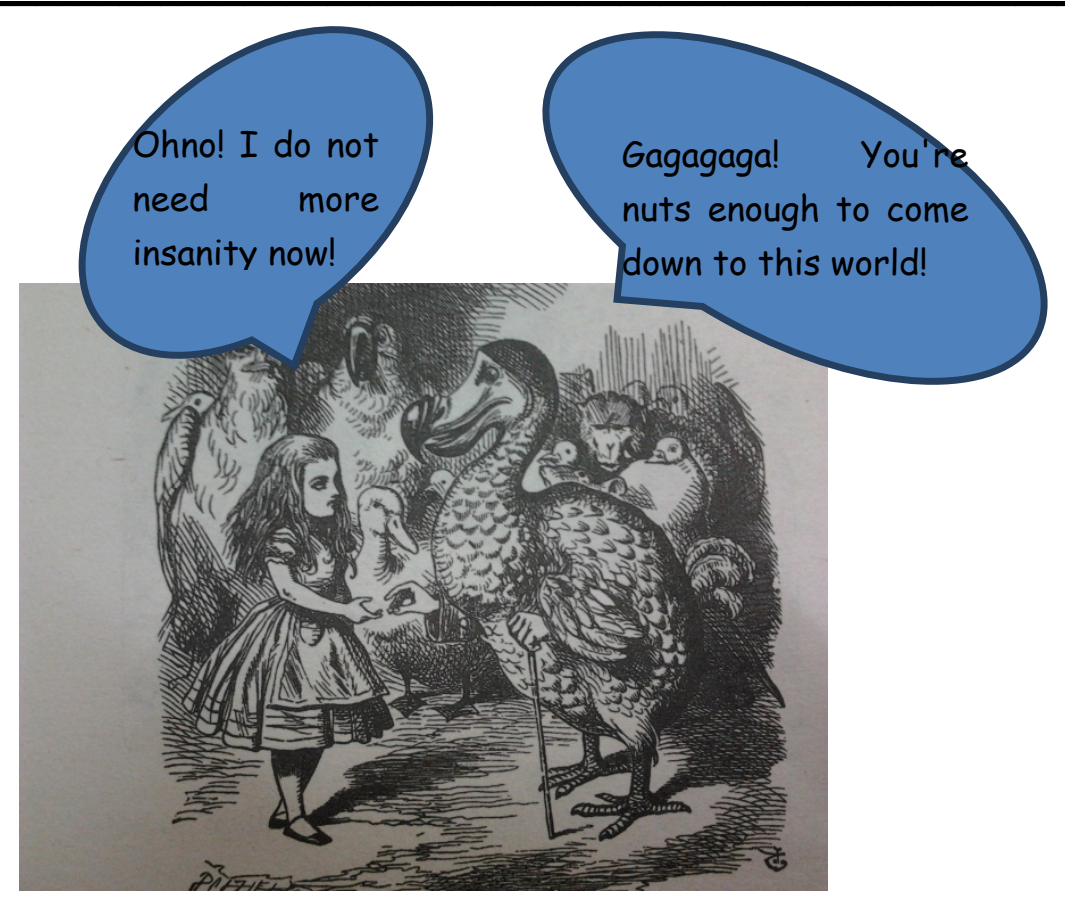

Figure 2. An example of an untraditional reading class created by the teacher

\begin{tabular}{|ll|}
\hline & Vocabulary: \\
\hline a. & Insanity: crazy, mad, nuts \\
\hline b. & $\begin{array}{c}\text { Thimble: cover of an object or of } \\
\text { something edible }\end{array}$ \\
\hline
\end{tabular}

This method is tried in classes $6 \mathrm{~A}$ and $5 \mathrm{~B}$ though the researcher has introduced reading method $\mathrm{B}$ to them in the end for the purpose of comparing which method they prefer. In class $6 \mathrm{~A}$, the researcher has realized the girls' shyness and that there is a leader among them, who speaks English well and who has participated quite good with the researcher. She has 


\section{Macrothink}

volunteered to read 'Alice's' speech and no other girls have shown any willingness to read the the bird's part, 'Dodo', so the researcher has read it. The student has toned the words correctly as if she were on stage performing her part; also her accent is almost in good English. Then, the researcher has acted out the vocabulary words given by acting crazy for the word 'insanity' and by unwrapping a toffee and giving the cover to one girl to present the word 'thimble'. The active girl has smiled as the words have been demonstrated, but as for the other four girls, they have exchanged looks and tried to hide their smiles.

The responses from the boys have been different because many boys have volunteered to act out the characters and some have guessed the meaning of the words correctly during the demonstration.

\subsection{Reading Method B}

"We beg your acceptance of this elegant thimble"; and when it had finished this short speech, they all cheered.

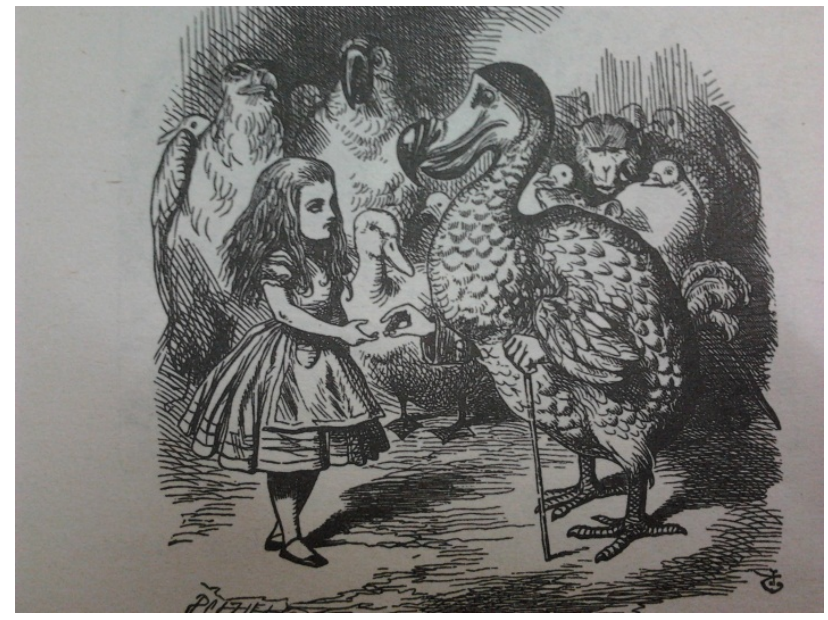

Figure 3. An example of a traditional literature class

As with the other two classes, the two reading methods have been introduced to the students, but this method has been instructed in the classroom. Four girls from class $6 \mathrm{~B}$ have preferred this method and no boys from class 5A have enjoyed it. The girls' reactions are almost similar to the girls' reactions in 6A, however, they have shown better responses as the researcher has asked questions like 'Who would like to read?' and 'Why does the bird think Alice is nuts?'. Teaching vocabulary has varied in this method as the researcher has explained the words and has written down the meanings on the board for them to copy, which the students have also participated well in. 


\section{Macrothink}

On the other hand, there has been more of a pull from the researcher to make the students answer in class 5A. All four students have found it normal to read the words and to answer the questions given as if they have been expecting that. Two students have asked if they could read the words in the bubbles, but that strategy has not been assigned for this class.

\section{Results}

The characters are presented as they are, except that a teacher has modernized the words that are used in real life, and it has been observed that reading method A is interesting to sixteen students because it is innovative and simpler that many would like to act the characters' parts, and the other half would prefer reading method B because they have been used to it since grade two. The results of the study are classified according to students' reading preferences in all four classes after implementing the surface level factors:

\subsection{Reading Method A Preferences}

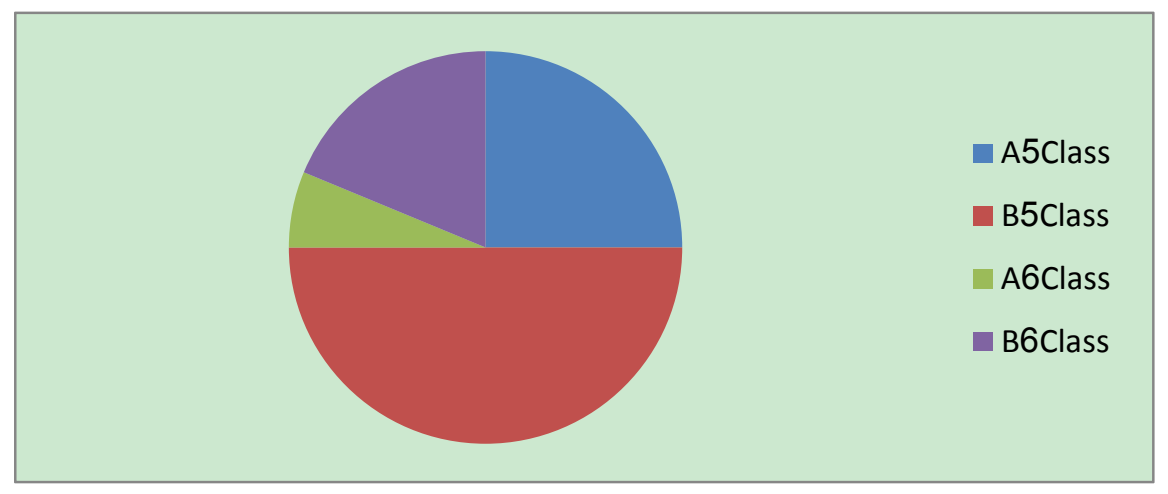

\subsection{Reading Method B Preferences}

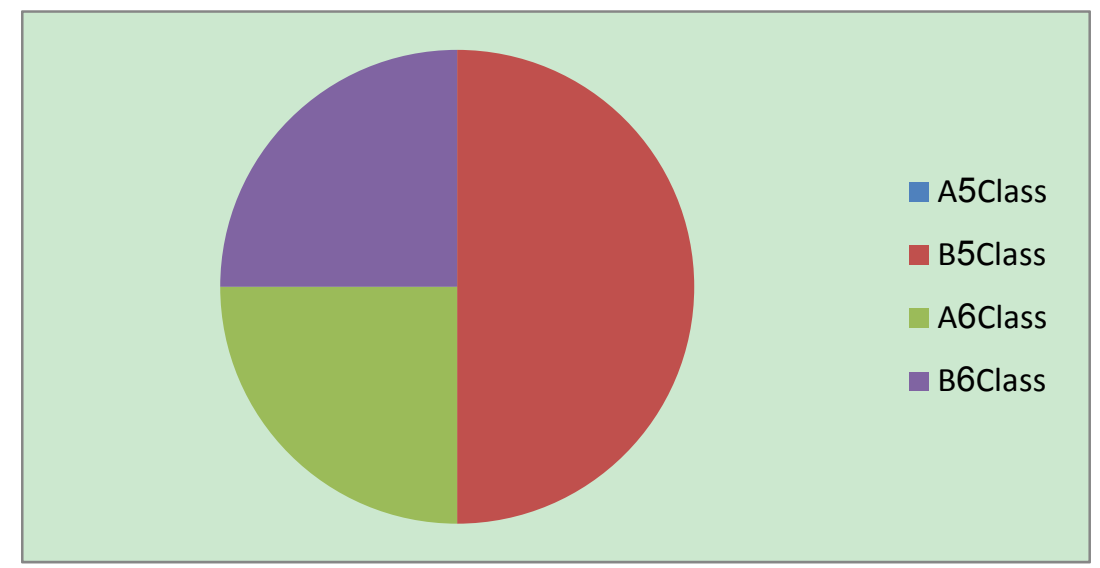

Though half of the students have shown interest in reading method B, the researcher has considered the surface level components and the outcomes of the case study along with the reasons behind favoring the two methods. In conclusion, reading method $\mathrm{A}$ is more suitable as it is something new to them and has shown productivity, whereas, reading method B is 
traditional and has not added something new as some students have told the researcher that's how they study at school, so anything new may be a new worry to them which they'd rather not endeavor. Therefore, the five psych-education factors the researcher has considered when deciding on which reading method best suits these students':

- genders

- thinking abilities

- English Language level

- environments, and

- familiarities with the story.

These factors would bring up the teaching methods in conducting a reading class, which in return, would intrinsically motivate the students by bridging their mentalities and behaviors to the modern way of learning literature. In order to follow up with the factors mentioned, a teacher should keep on up-dating the portfolio of every student, for example the boys have enjoyed reading method $\mathrm{A}$ more than reading method $\mathrm{B}$, therefore, the teacher could sometimes ask the boys to prepare play roles according to certain instructions given. Another example is grouping the weak students with other students and distributing jumbled speeches, which they have to put them in order and to explain them in turns to the class. The point of this discussion is that the teacher should always seek for ways to educate the students, disregarding their levels. Moreover, the teacher's aim is to make the students to read and to understand the story for class participation and to achieve well in their exams. This may lead the students to subconsciously understand the English speaking world and its cultures since they are eager to learn the language without feeling the burdens of acquiring it throughout their scholastic years.

\section{Conclusion}

Most classrooms in the Middle East consist of students of different levels. An example of this fact is the case study performed in the targeted school where every class form has students whose English Language level varies from one another. Moreover, most of the students' English level is average and they are on the verge of entering high school in a few months. Besides the academic analysis, the students' behaviors generally show some timidity due to their lack of confidence in expressing in the targeted language, so it is unlikely to receive sincere replies or questions from them as a teacher just lamely asks questions. Therefore, a teacher should genuinely consider the class' needs by not being a cohesive or a traditional teacher, but a modern one by designing a portfolio for every student to follow up with the their academic and social skills during a year or a term to choose the right methods for a reading class or any other lessons. For example, if most of the students cannot read fluently or easily, then it would be essential to adapt the syllabus accordingly by making it more demonstrative and meaningful to them rather than just reading and asking questions. On the other hand, if most of the students are quite good, and then following an assigned syllabus would not be a problem, however, the teacher must still take into account the other students that need help in reading comprehension and/ or in vocabulary because what makes a modern teacher good is promoting the weak students to a higher language and comprehension levels. 


\section{MInstitute Macrothink $_{\text {Intion }}$}

For many decades, the language has encountered severe changes among the scholars due to many negative interferences such as the unavailability of acquiring the language, learning at older stages or acquiring the language improperly in its structure or accent. As these defects have passed from one generation to another, the students have indirectly urged the teachers to either seek for innovative strategies when teaching or, when older, they simply push themselves to learn the language from ESP courses, universities, their jobs and from their surroundings. The summary of this point is briefly illustrated on the next page from the dawn of the last century until nowadays.

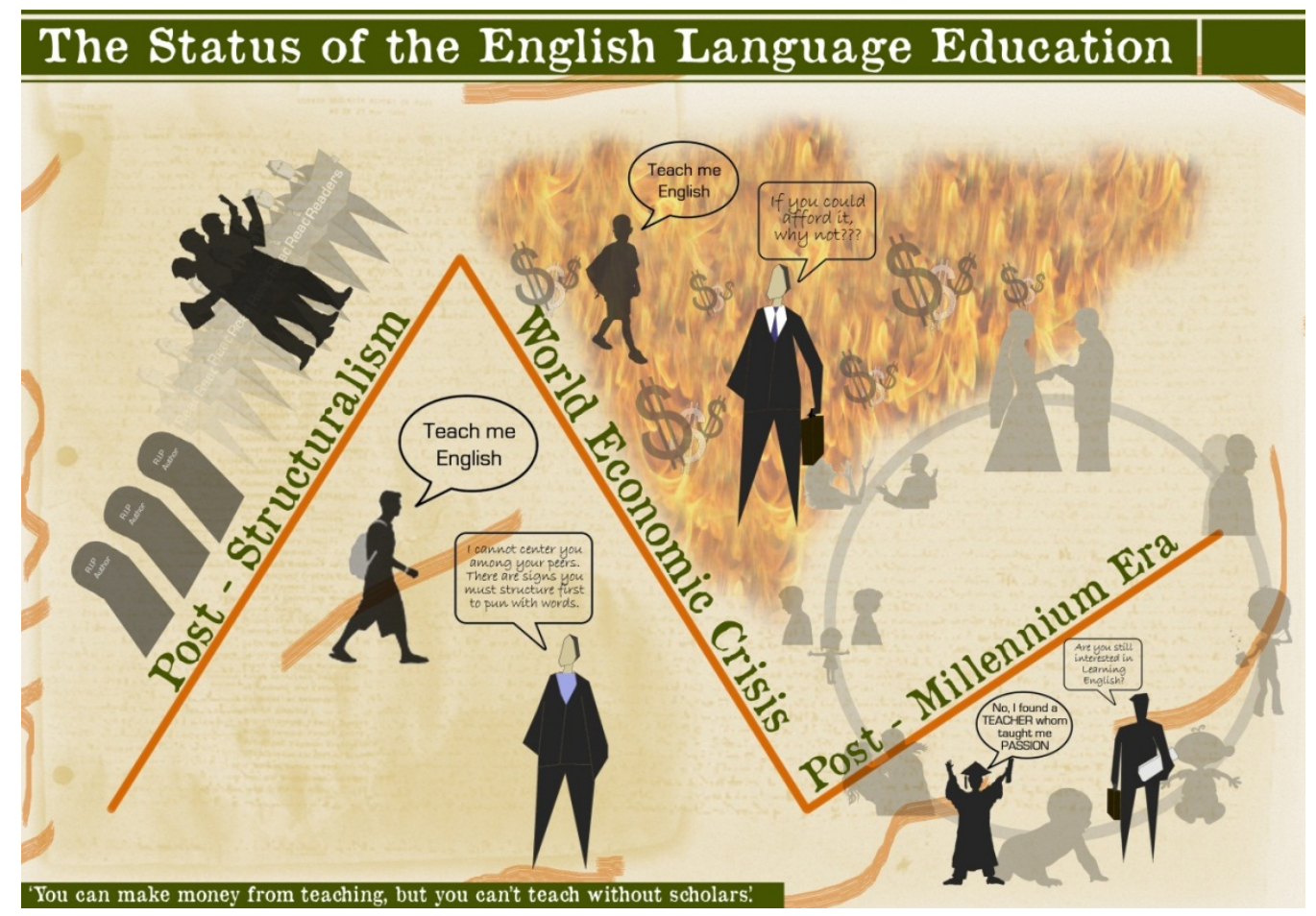

Figure 4. The rise and fall of the English Language since the start of the last century

The post-millennium structuralism movement is a rise of the common people from immobility; the invasion of the inferiors in the chaotic world. In this case, literature is seen through a new dimension, the dimension of the learner and not the educator. Learners do not want to sit down and read stories from books for a whole lesson, they want to act out, mimic characters, discuss real-life matters and look for what is interesting, hilarious, innovative, updated, simplified and educational, and that would never be inevitable without you, the teacher.

To sum up, the new teaching philosophy is as light as it seems and just requires a little bit of effort from an educator to extrinsically motivate the learners, and according to Otis (2005), it is vital to seek for activities that extrinsically motivate the students to participate because many students, nowadays, are eager to learn for materialistic needs by scoring certain grades to graduate from schools and universities, and that's one of the main reasons why the English Language is not taken into depth. Moreover, the earlier they are trained on being motivated extrinsically, the better they would perform at later stages. Therefore, an educator should 


\section{Macrothink

extrinsically motivate them by designing innovative, easy-to-learn teaching materials and forcing them to study in classrooms before depending on them to work alone.

\section{References}

Alptekin, C. (2002). Towards Intercultural Communicative Competence in ELT. ELT Journal, 56(1), 57-64. http://dx.doi.org/10.1093/elt/56.1.57

Carroll, L. Alice's adventures in wonderland ( $1^{\text {st }}$ ed.). Edited by Nancy Willard, New York: Aladdin Paperbacks. An imprint of Simon and Schuster Children's Publishing Division, 2000. pp. 26-27.

Foucault, M. (1988). Politics, philosophy, culture: interviews and other writings 1977-1984. Edited by Lawrence D. Kritzman, New York: Routledge. p. 118.

Long, M. N. (1987). A feeling for language: The multiple values of teaching literature. In Brumfirt, Ch. J, Carter, R., Literature and language teaching. Oxford: Oxford University Press. p. 289.

Otis, N., Grouzet, F. M., \& Pelletier, L. G. (2005). Latent Motivational Change in an Academic Setting: A 3-year longitudinal study. Journal of Educational Psychology, 97(2). 170-183. http://dx.doi.org/10.1037/0022-0663.97.2.170

Rogers, E. (2003). Diffusion of innovations (5th ed.). New York: Free Press. p. 137.

Selden, R. et al. (2005). A reader's guide to contemporary literary theory (5th ed.). GB: Pearson Education Limited. p. 3.

\section{Copyright Disclaimer}

Copyright reserved by the author(s).

This article is an open-access article distributed under the terms and conditions of the Creative Commons Attribution license (http://creativecommons.org/licenses/by/3.0/). 